\title{
ARTICLES
}

\section{MONGOLIA AND NORTHEAST ASIA}

\section{Choinkhor J}

The 1990s have been marked by abrupt changes in economic and political situation in the world. The easing of international tensions is expected to lead to a more security and economic growth.

Today we live in a world where the economics is the dominant force in the international relations.

The Asia Pacific region became the fastest developing area in the world. Only going toward with world and regional economic cooperation, individual nation-states can survive and develop. The human economic activities are becoming more and more interdependent. The internationalization and regionalization is a rapidly on-going process.

An increase is felt as far the importance of the Northeast Asia in the world and Asia-Pacific community due to its strategic positioning in the new world order devoid of any East-West conflict. The emphasis is to be shifted to the economic development and integration issues.

Within these shifting components an opportunity exists for the Northeast Asia to act as a regional economic cooperation group because of various predominant characteristics such as size, geographic position, natural and human resources, tech-nology and the powers involved in. Vision is focused in support of local development through a regional framework.

The region has all three classical production factors namely capital, land and labor plus upcoming information based economy.

Companies, organizations and individuals of the countries in the region today have more wide vision than politicians and no longer view their mission in a national framework but also look on regional prospects they perceive the region as one market and are in fact setting up strategies and restructuring themselves in a regional dimension.

Although the vision involves many aspects I will endeavor to treat the subject by mentioning some major aspects of the current regional scenario which would help propel the vision.

During the four years of economic reforms Mongolia and Northeast Asian nations with market economies are engaged in growing exchange of people as 
well as commodities Businessman, government officials, scholars and students from each country visited the other in order to find opportunities for building mutually beneficial relationships.

In view of the typical geographical location and various other factors, Mongolia is believed to face a unique and in many respects disadvantages situation in terms of opportunities to pursue economic cooperation with NEA, namely in thermo of mineral resources, being a bridge between the two big markets, China and Russia.

Some of characteristics are listed below:

\section{POLITICAL WILLINGNESS}

The full development of regional economic ties depends on political willingness. The countries are now more readily con-sulting with each other and discussing political, security and eco-logic issues. They deal realistically, not ideologically, with new international circumstances after the end of the superpower ri-valry. The regional security cannot be considered separately from the regional economy. But North-East Asia has been described as lagging behind every other world area in constructing explicit, cooperative arrangements. Indeed Asia appears strikingly under-institutionalized. A late start in institutionbuilding APEC was fi-nally launched only in 1989. We have to construct new institu-tions to bridge this gap despite diversity of governmental and societal forms, difference in economic structure, output and per capita income. Beside the bilateral relations it is important to reinforce the UN and ensure cooperation with other international institutions, especially APEC and PECC. APEC structure will not inhibit innovation but can provide a valuable foundation for future constructions. It will be essential to maintain dialogues at various levels. I would like to mention that the Government of Mongolia had offered to host the seventh meeting of the ESCAP Steering Group of the Committee for regional economic cooperation

\section{REGIONAL ECONOMIC DEMOCRACY}

We have adopted as basic state policy the opening of the Mongolian economy to the outside world. Bringing about industrial growth through harnessing of the resources of the region in the shape of capital, technology and parking perceive sound to be achieved in progressive stages. Serious efforts should be made to foster solidarity and closer economic co-operation among the countries of the region, having regard to the fact that in the economic situation prevailing in some of the financial institutions and developed countries 
themselves, it would be extremely difficult to obtain the assistance of the type and extent required for development. The time is ripe for promoting industrial co-operation between the countries concerned through bilateral and tripartite arrangements in relation to specific projects, such as downstream activities in relation to natural resources. We are feeling that attention should also be focused on medium and small projects. I would like to underscore the possibility of co-operation on industrial plants to meet the regional requirements of essential commodities through joint or tripartite venture projects in a realistic and effective manner taking into account geographical and infrastructural factors. The private sector should be actively asso-ciated and encouraged to take part. The resources available for regional inputs, both in the shape of capital and technology, would be considerably enhanced by the participation of the private sec-tor.

The successful conclusion of the Uruguay Round was truly a remarkable achievement of a global importance. The decision on establishment of the World Trade Organization, a new set of multilateral trade rules, new disciplines designed to creation of a fair and market-oriented agricultural system, improvements of dispute settlement system will give a boost to development and growth. Mongolia is quite keen to become an APEC, PECC and GATT member as rapidly as possibly, looking towards member-ship in the WTO when it enters into force. We are aware that the membership assumes not only benefits but commitments.

\section{PHYSICAL LINKS}

The most challenging factor to the cooperation process is the transport infrastructure which remains seriously inadequate. Concerning Mongolia, after the present economic situation improves the lack of infrastructure, due to antiquated, inefficient and idle for lack of spare parts road fleet and extensive air network, will be a major constraint on regional and national development given the country's large size and widespread distribution of natural resources. Disparity in the growth impulse concerns Mongolia by its land-locked position. Mongolia concluded agreements on transit to have access to the sea with our two neighboring powers in accordance with the international law.

Development of railway systems throughout the region can lead to a challenge of continental versions built on massive scale to maritime mobility. On the other hand an efficient utilization and maintaining existing infrastructure assets such as Trans-Siberian, Trans-Mongolian (connecting Ulaanbaatar with Beijing) could be given an immediate priority in this field. 
Integrated planning system, formulation of the regional action programmed would ensure the smooth transition to the phase of the Transport and Communication system in Asia and the Pacific.

Mongolia has expressed its desire to join the Asian Highway project. This project is intended to link the roads of Asian countries with those of European and Middle Eastern Highway system. The project's aim is to assist and coordinate international by-road haulages by means of setting Asian Highway system which will connect all capitals, industrial centers, important ports and tourist, commercial centers. This project has also been worked out in order to assist development of national and international trade and tourism, stimulate economic cooperation and cultural ex-changes between nations of the region.

\section{IY. FOREIGN DIRECT INVESTMENT}

Among the factors that exert influence on the co-operation issues, foreign direct investment has become increasingly important. Foreign investment is one of the most effective means of transferring technical knowledge from the world's pool of ex-isting experience about how to produce most efficiently.

But it is very difficult to create economic environment necessary to attract foreign investment at this stage Mongolia is experiencing. The Mongolian Government places great emphasis on the improvement of the investment conditions. This has been regarded as an essential aspect in the pursuance of the open policy. In order to generate flow of investments within the regional context stress should be laid on the need for creating stable but flexible relations through establishment of promotion of bilateral investment and double taxation agreements and introduction of adequate internal laws and its implementation which are consid-ered to be as a legal basis for cooperation in this field.

In the past few years, Mongolia has promulgated several laws and regulations concerning external economic regulations, including a new Foreign Investment Act which offers a wide array of incentives, especially to the preferred pioneer enterprises, including tax holiday and insurance against political risks. It has concluded agreements on reciprocal promotion and protection of investments with 11 countries and a bilateral agreement for the operation of the political risk insurance programmers of the Overseas Private Investment Corporation (OPIC) and signed agree-ments on the avoidance of double taxation with 5 countries, in-cluding PRC and RK. Mongolia is going to be a member of World Bank's International Centre for Settlement of Investment Disputes (ICSID) and signed the Convention on Establishment of Multilat-eral Investment Guarantees Agency (MIGA). We have clearly borne in mind that, owing to our limited 
experience in dealing with the outside world, problems exist with regard to administrative and managerial aspects.

\section{Y. NATURAL RESOURCES AND THEIR EXPLOITATION}

The aggregate resource base of the region can be consid-ered as abundant. But the wear manufacturing and service sec-tors in some countries of the region conduce to high import dependence. Given high transmission and distribution losses, and the high unit energy consumption in several manufacturing in-dustries energy efficiency is another key area of concern. To this end, an energy audit, efficiency, conservation and correct pricing (according to the international hard currency prices) are to be adjusted for cooperation purposes.

\section{YI. POST RIO SUMMIT DEVELOPMENT}

One of the most pressing problems confronting the international community is that of the protection and improvement of the human environment. This problem has been given priority within the framework of the UN and other international organizations. It is widely shared that unregulated trade liberalization will harm the environment, but the positive potential of freer trade is also seen if environmental issues are taken into account.

Due to harsh and extreme climate Mongolia is highly con-cerned about potential impacts global climate change could have on its traditional economy and natural landscape. Mongolia has just begun to monitor the emission of greenhouse gases into the atmosphere. Commercially harvested plants without reforestation, soil erosion, and overgrazing, desertification, energy and air pollution are challenges to the global development. Most of industrial developments have occurred in basins of large riv-ers (concerning Mongolia it is the Selling River system). In adulation industrial pollution is highly localized. Water pollution caused by this threatens the ecological health of Lakes Baikal and Hubsugul. Mongolia pursues an agreement with China and Rus-sia on transboundary water issues.

It is not secret that next to Europe Asia has no progress in folding environmental considerations into regional system of rules and procedures. We need a mechanism for identifying and analysing regional environmental issues within the global system, in- evolving the countries concerned, UN agencies and initiatives of NGOs.

There is a need of harmonization of environmental stand-ards, including Eco-labeling \& Eco-packaging Regulations and restriction of unfair competition 
of lower-cost goods produced under conditions below international standards. But attention should be focused on the fact that environmental purposes cannot be invoked for harmful trade restrictions.

\section{YII. DEBT BURDEN}

External debt burden of many countries has increased significantly. This has resulted in negative economic growth affecting vitally the overall development and integration process. Remedial measures to limit the economic impact of this problem have so far not been very successful. Instead, some of these remedial measures have had an impact which could be termed as negative. There is a need to outline suitable, for both debtors and creditors, and durable solution. This area where we can have fruitful discussions and consultations.

\section{YIII. I.T. and Cooperation}

Fast, reliable communications are important to the effective co-operation and integration. Information flows are probably growing faster than any other transaction. It may already exceed money flows in the fees, royalties and profits they generate. An analysis of the information system requirements reveals the com-mon need to have fast and accurate access to collated informa-tion, documents in current or recent use on various issues of mutual interest. To investigate how an extensive use of I.T. can contribute to the co-operation and the promotion of technology transfer.

Finally I would like to suggest some forms of future cooperation between Mongolia and the rest of NEA.

The abundant supply of natural resources and raw materi-als in Mongolia are certainly the most attractive features. The pressing problem for Mongolia is the lack of capital and technology. Meanwhile secure supply of natural resources is regarded as the most critical issue for developed economies like Japan and Korea. Mongolia could become such a secure source.

The joint development project should be based upon the principle that the developed economies would supply the equipment, machinery and materials required for development on a long term deferred payment basis and in turn would be pro-vided overlong period of time with agreed quantities of natural resource developed in Mongolia.

Together with the large scale projects for exploiting natural resources such as coal, oil, copper projects new fields of industry should be considered, it is thought that manufacturing industry should be included in the execution of the 
projects on the assumption that the market economies of NEA would be importing semi-processed goods with more value added in turn.

As a secondary-effect of switching over to market economy the potential for cooperation between Mongolia and other NEA countries in the service sector is emerging. The entrance of foreign companies into Mongolia is creating a heavy demand for office buildings, showrooms, exhibition halls, distribution center, etc.The common forms of Mongolia's regional cooperation may be the supply of plants and equipment including payments in-end prod-ucts, contracting and joint production it is well known the former usually takes the form of the delivery of complete plants, equipments or production lines against payment in manufactured products or raw materials extracted by means of the above equipment.

Joint production is mostly facilitated through the extensive transfer of technology and form of purchases of license, including the supply line or whole factory. 